\title{
Nanofluid flow in a microchannel with inclined cross-flow injection
}

\author{
Afshin Shiriny ${ }^{1} \cdot$ Morteza Bayareh $^{1} \cdot$ Afshin Ahmadi Nadooshan $^{1}$ (i) \\ (c) Springer Nature Switzerland AG 2019
}

\begin{abstract}
This paper investigates forced convection of water $/ \mathrm{Al}_{2} \mathrm{O}_{3}$ nanofluid flow in a microchannel with inclined cross-flow injection on the lower wall. There are a number of injecting holes on its lower wall. Other walls are insulated. The effect of different parameters including injection angle and number of injections on slip flow and heat transfer is investigated. It is concluded that increasing the injection angle up to $94^{\circ}$ lead to an enhancement of the slip velocity and the Nusselt number on the microchannel walls. The results demonstrate that maximum heat transfer corresponds to the injection angle of $94^{\circ}$. It is revealed that the variation of Nusselt number decreases with the number of injection. As the volume fraction of nanoparticles increases, the heat transfer rate increases.
\end{abstract}

Keywords Forced convection · Nanofluid · Slip velocity · Inclined injection · Microchannel

\section{Introduction}

Fluids play a vital role in cooling and heating systems in industries. Their thermal conductivity is enhanced by addition of solid nanoparticles. The first observations of the thermal conductivity of nanofluids were reported by Masuda et al. [1]. Nazari et al. [2] demonstrated that the heat transfer of the nanofluid increases compared to the base ones. Numerous studies have been carried out on the use of microchannels in heat exchangers and heat rejected systems due to the small dimensions of these channels and their high efficiency. Raisi et al. [3] demonstrated that the Nusselt number $(\mathrm{Nu})$ enhances with the slip coefficient for Reynolds numbers higher than 100. Akbarinia et al. [4] revealed that at a constant Reynolds number (Re), Nu enhances with the inlet velocity and it does not change with the volume fraction of nanoparticles $(\varphi)$. Anoop et al. [5] studied forced convection heat transfer of water/silica nanofluid numerically and experimentally and demonstrated that the nanofluid exhibits Newtonian behavior for the volume fractions less than $7 \%$. Togun et al. [6] considered heat transfer of nanofluids (water $/ \mathrm{Al}_{2} \mathrm{O}_{3}$ and water/CuO) in a microchannel with double forward-facing steps. They revealed that $\mathrm{Nu}$ is higher on the second step in comparison with the first one. It was demonstrated that the heat transfer enhances with the volume fraction of nanofluids. The results of Nemati et al. [7] revealed that the average Nusselt number increases with $\varphi$ and decreases with the magnetic field intensity. Jung et al. [8] evaluated the heat transfer of a nanofluid in a rectangular microchannel and found that Nu increases by increasing $\varphi$ and Re. Olawale [9] evaluated the effect of injection flow in diverging and converging microchannel on heat transfer and hydrodynamics of a nanofluid. He found that the velocity distribution is an increasing function of Reynolds number. Malvandi et al. [10] demonstrated that velocity gradient close to the walls increases with the magnetic field. Afrand et al. [11] concluded that the slip velocity on the walls increases with the magnetic field intensity and heat transfer increases in the vicinity of the walls due to the accumulation of nanoparticles in this region. Their study corresponded to water/FMWNT nanofluid. Li and Kleinstreuer [12] simulated heat transfer of water and water/CuO nanofluid in a trapezoidal microchannel and showed that thermal performance of nanofluid is higher than that of pure water. They revealed that as the volume

Afshin Ahmadi Nadooshan, ahmadi@sku.ac.ir | 'Department of Mechanical Engineering, Shahrekord University, Shahrekord, Iran.

SN Applied Sciences (2019) 1:1015 | https://doi.org/10.1007/s42452-019-1050-y 
fraction increases, heat transfer rate and pressure drop increase. Aina and Malgwi [13] investigated the combined effects of magnetic field and suction/injection on natural convection heat transfer in an inclined microchannel with porous media. They demonstrated that thermal boundary later thickness increases and decreases with the injection and suction flow rates, respectively. Hence, thermal performance decreases and increases under the influence of injection and suction, respectively. In heat channels, the fluid temperature near the hot surfaces is always higher than the central of the channel. Thus, if low temperature fluid can be mixed with the hot one adjacent to the target surface, the heat transfer rate increases significantly. For this purpose, various techniques such as injection and suction of fluids have been proposed. In most of the studies, nanofluids have been used as a cooling fluid to improve the heat transfer. Jha and Aina [14] reported that the volumetric flow rate increases by increasing injection and suction, while the heat transfer decreases. Also, the possibility of a return flow on the cold wall decreases with the Knudsen number. López et al. [15] found that Nu increases on the hot wall of a porous microchannel and decreases on its cold wall by increasing $\varphi$ and injecting the flow. Jalali and Karimipour [16] reported that $\mathrm{Nu}$ increases with $\mathrm{Re}$ and $\varphi$. Convective heat transfer and entropy generation of $\mathrm{Ag}-\mathrm{MgO} /$ water hybrid nanofluid in microchannel are discussed by Uysal and Korkmaz [17]. They found that heat transfer increases as the volume fraction of hybrid nanofluid increases. In addition, it was reported that the entropy generation decreases due to the heat transfer and increases due to fluid friction. Akinshilo [18] studied the effect of magnetic field on heat transfer of a nanofluid in a converging or diverging porous channel with injection flow. It was concluded that $\mathrm{Nu}$ increases with the magnetic field strength. They studied the influence of Reynolds number, volume fraction of nanoparticles and expansion angle on heat transfer and fluid friction. Evaluation of the effect of nanofluid on convective heat transfer has been considered for different geometries [19-22].

Present simulations evaluate forced convection of water $/ \mathrm{Al}_{2} \mathrm{O}_{3}$ nanofluid in a microchannel considering inclined injection on the lower wall. The main objective of the present work is to investigate the effect of injection angle and number of injections on thermal performance of a heat microchannel. Their influence on velocity distribution, temperature profile and slip velocity is discussed.

\section{Problem statement}

Schematic of a microchannel $(L \times H)$ is shown in Fig. 1. The water $/ \mathrm{Al}_{2} \mathrm{O}_{3}$ nanofluid enters the microchannel with the velocity of $U_{c}$ and the temperature of $T_{c}=293 \mathrm{~K}$ and exits

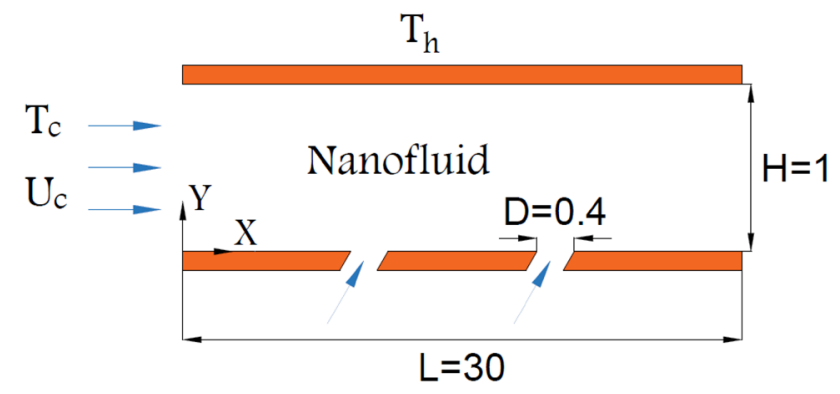

Fig. 1 Schematic of the microchannel with inclined cross-flow injection

Table 1 Thermophysical properties of water $/ \mathrm{Al}_{2} \mathrm{O}_{3}$ nanofluid [16]

\begin{tabular}{lllll}
\hline$\varphi(\%)$ & $\rho_{n f}\left(\mathrm{~kg} / \mathrm{m}^{3}\right)$ & $\mu_{n f}(\mathrm{~Pa} \mathrm{~s})$ & $k_{n f}(\mathrm{~W} / \mathrm{m} \mathrm{K})$ & $\left(c_{p}\right)_{n f}(\mathrm{~J} / \mathrm{kg} \mathrm{K})$ \\
\hline 0 & 997.1 & $8.91 \times 10^{-4}$ & 0.613 & 4179 \\
2 & 1056.5 & $9.37 \times 10^{-4}$ & 0.653 & 3922.4 \\
4 & 1116 & $9.87 \times 10^{-4}$ & 0.695 & 3693.3 \\
\hline
\end{tabular}

from the microchannel output after cooling its walls. Table 1 presents thermophysical properties of the nanofluid. The upper wall temperature is constant, $T_{h}=303 \mathrm{~K}$ and the lower one is insulated. A number of holes $(\mathrm{d}=0.4 \mu \mathrm{m})$ are mounted on lower wall through which the nanofluid is injected into the microchannel with the angle of $\beta$. The flow is Newtonian, laminar and steady. The slip boundary condition is imposed on walls of the microchannel. The terms of thermal creep and temperature jump are ignored. The simulations are performed in three sections. In the first section, the effect of the angle of injection is evaluated. The second section provides the influence of the number of injections, and in the third section, the effect of $\varphi$ on the velocity and temperatures distributions is investigated. Re for the nanofluid flow is equal for the channel input and the injection parts. In the present simulation, $R e=10$, the slip coefficient on micro-channel walls is $B=0.1$ and $\varphi=2 \%$.

\section{Governing equations}

Continuity, momentum and energy equations that are governing equations of nanofluid flow are as follows, respectively [16]:

$\frac{\partial u}{\partial x}+\frac{\partial v}{\partial y}=0$

$u \frac{\partial u}{\partial x}+v \frac{\partial u}{\partial y}=-\frac{1}{\rho_{n f}} \frac{\partial p}{\partial x}+\frac{\mu_{n f}}{\rho_{n f}}\left(\frac{\partial^{2} u}{\partial x^{2}}+\frac{\partial^{2} u}{\partial y^{2}}\right)$

$u \frac{\partial v}{\partial x}+v \frac{\partial v}{\partial y}=-\frac{1}{\rho_{n f}} \frac{\partial p}{\partial y}+\frac{\mu_{n f}}{\rho_{n f}}\left(\frac{\partial^{2} v}{\partial x^{2}}+\frac{\partial^{2} v}{\partial y^{2}}\right)$ 
$u \frac{\partial T}{\partial x}+v \frac{\partial T}{\partial y}=\alpha_{n f}\left(\frac{\partial^{2} T}{\partial x^{2}}+\frac{\partial^{2} T}{\partial y^{2}}\right)$

Governing boundary conditions are:

$$
\begin{array}{ll}
u=u_{c}, v=0, T=T_{c} & \text { For } x=0,0 \leq y \leq H \\
\frac{\partial u}{\partial x}=0, v=0, \frac{\partial T}{\partial x}=0 & \text { For } x=L, 0 \leq y \leq H \\
u=u_{s}, v=0, \frac{\partial T}{\partial y}=0 & \text { For } 0 \leq x \leq L, y=0 \\
u=u_{s}, v=0, T=T_{h} & \text { For } 0 \leq x \leq L, y=H
\end{array}
$$

where $u_{s}$ is the slip velocity on the walls of the microchannel and is obtained using the following relationship:

$u_{s}= \pm b\left(\frac{\partial u}{\partial y}\right)_{y=0, h}$

where $b$ is dimensional slip coefficient. The positive and negative signs are respectively related to the lower and upper walls of the microchannel. It should be noted that at the microchannel output, the flow is fully developed hydrodynamically and thermally.

By defining the following parameters, the above equations are dimensionalized:

$$
\begin{aligned}
& X=\frac{x}{h}, Y=\frac{y}{h}, U=\frac{u}{u_{c}}, V=\frac{v}{u_{c}} \\
& \theta=\frac{T-T_{c}}{T_{h}-T_{c}}, P=\frac{p}{\rho_{n f} u_{c}^{2}}, \operatorname{Re}=\frac{u_{c} h}{\vartheta_{f}}, \operatorname{Pr}=\frac{\vartheta_{f}}{\alpha_{f}}
\end{aligned}
$$

Hence, the dimensionless governing equations are:

$\frac{\partial U}{\partial X}+\frac{\partial V}{\partial Y}=0$

$U \frac{\partial U}{\partial X}+V \frac{\partial U}{\partial Y}=-\frac{\partial P}{\partial X}+\frac{\vartheta_{n f}}{\vartheta_{f} R e}\left(\frac{\partial^{2} U}{\partial X^{2}}+\frac{\partial^{2} U}{\partial Y^{2}}\right)$

$U \frac{\partial V}{\partial X}+V \frac{\partial V}{\partial Y}=-\frac{\partial P}{\partial Y}+\frac{\vartheta_{n f}}{\vartheta_{f} \operatorname{Re}}\left(\frac{\partial^{2} V}{\partial X^{2}}+\frac{\partial^{2} V}{\partial Y^{2}}\right)$

$U \frac{\partial \theta}{\partial X}+Y \frac{\partial \theta}{\partial Y}=\frac{\alpha_{n f}}{\alpha_{f} \operatorname{Re} \cdot \operatorname{Pr}}\left(\frac{\partial^{2} \theta}{\partial X^{2}}+\frac{\partial^{2} \theta}{\partial Y^{2}}\right)$

In addition, the properties of the nanofluid are obtained using the following relations [16]:

$\rho_{n f}=(1-\varphi) \rho_{f}+\varphi \rho_{s}=0$

$\alpha_{n f}=\frac{k_{n f}}{\left(\rho c_{p}\right)_{n f}}$

$\left(\rho c_{p}\right)_{n f}=(1-\varphi)\left(\rho c_{p}\right)_{f}+\varphi\left(\rho c_{p}\right)_{s}$ $\mu_{n f}=\frac{\mu_{f}}{(1-\varphi)^{0.25}}$

$k_{n f}=k_{f}\left(1+\frac{k_{s} A_{s}}{k_{f} A_{f}}+c k_{s} P_{e} k_{s} \frac{A_{s}}{k_{f} A_{f}}\right)$

where $c=25,000$ is an experimental constant. $\mathrm{k}_{\mathrm{f}}=0.613 \mathrm{~W} /$ $\mathrm{mK}$ is thermal conductivity of the base fluid and $\mathrm{k}_{\mathrm{s}}=40 \mathrm{~W} /$ $\mathrm{mK}$ is that of nanoparticles. The ratio of molecular area of the base fluid and that of solid nanoparticles is as follows [16]:

$\frac{A_{f}}{A_{s}}=\frac{d_{f}}{d_{s}}\left(\frac{\varphi}{1-\varphi}\right)$

In addition, $\mathrm{P}_{\mathrm{e}}$ is define as follows:

$P_{e}=\frac{u_{s} d_{s}}{\alpha_{f}}$

$\mathrm{u}_{\mathrm{s}}$ is related to the effect of the Brownian motion and is calculated as follows:

$u_{s}=\frac{2 K_{b} T}{\pi \mu_{f} d_{s}^{2}}$

where the Boltzmann constant $\mathrm{K}_{\mathrm{b}}=1.3807 \times 10^{-23} \mathrm{~J} / \mathrm{K}$ and the molecular diameter of water and solid nanoparticles is $d_{f}=2 A^{\circ}$ and $d_{s}=40 \mathrm{~nm}$, respectively [16].

Hence, dimensionless governing boundary conditions are:

$U=1, V=0, \theta=0 \quad$ For $X=0,0 \leq Y \leq 1$

$\frac{\partial U}{\partial X}=0, V=0, \frac{\partial \theta}{\partial X}=0 \quad$ For $X=\frac{L}{H}, 0 \leq Y \leq 1$

$U=U_{s}, V=0, \frac{\partial \theta}{\partial Y}=0 \quad$ For $0 \leq X \leq \frac{L}{H}, Y=0$

$U=U_{s}, V=0, \theta=1 \quad$ For $0 \leq X \leq \frac{L}{H}, Y=1$

Dimensionless slip coefficient is defined as $B=b / H$. Hence, dimensionless slip velocity is:

$U_{s}= \pm B\left(\frac{\partial U}{\partial Y}\right)_{Y=0,1}$

The local Nusselt number $\left(\mathrm{Nu}_{\mathrm{x}}\right)$ is:

$N u_{x}=-\frac{k_{n f}}{k_{f}}\left(\frac{\partial \theta}{\partial Y}\right)_{Y=1}$

The average Nusselt number $\left(\mathrm{Nu}_{\mathrm{m}}\right)$ is:

$N u_{m}=\frac{1}{L} \int_{0}^{L} N u_{x} d X$ 
Table 2 Nusselt number and dimensionless velocity on the midpoint of the upper wall of the microchannel with four $60^{\circ}$ angle injection points for different grid resolutions

\begin{tabular}{llllllr}
\hline & $40 \times 400$ & $50 \times 500$ & $60 \times 600$ & $70 \times 700$ & $80 \times 800$ & $90 \times 900$ \\
\hline $\mathrm{Nu}$ & 1.5173 & 1.5174 & 1.5174 & 1.5166 & 1.5161 & 1.5161 \\
$U$ & 0.5282 & 0.5298 & 0.5305 & 0.5323 & 0.5327 & 0.5331 \\
\hline
\end{tabular}

\section{Results}

Forced convection heat transfer of water $/ \mathrm{Al}_{2} \mathrm{O}_{3}$ nanofluid in a microchannel is evaluated. First, grid study and then validation are presented. The effect of the injection angle, the number of injections and different values of $\varphi$ on slip velocity, temperature field and heat transfer of nanofluid will be presented in the next sections.

\subsection{Grid study}

The values of the Nusselt number and dimensionless velocity on the midpoint of the upper wall with four $60^{\circ}$ angle injection points are shown in Table 2 for various grid resolutions. The difference between the results for the grid resolutions of $40 \times 400$ and $50 \times 500$ is negligible. Therefore, the grid with the grid resolution of $40 \times 400$ is selected for further simulations.

\subsection{Validation}

Validation of present numerical method is carried out in comparison with the results of Jalali and Karimipour [16] who investigated the effect of vertical injection on the slip velocity in a microchannel. The non-dimensional slip velocity profile is presented in Fig. 2 , where $R e=10$ and $\varphi=2 \%$. The results obtained from the present simulations are in agreement with those presented by Jalali and Karimipour [16] qualitatively. They showed that the slip velocity peaks increases with the channel length. In addition, as the slip coefficient increases, the rate of enhancement increases.

Also, in Fig. 3, the changes of $\mathrm{Nu}_{\mathrm{x}}$ as a function of microchannel length is compared with the reference results for $\operatorname{Re}=100, \mathrm{~B}=0.1$ and $\varphi=2 \%$.

\subsection{Effect of injection angle}

In Fig. 4, variations of dimensionless velocity of nanofluid along the line $X=0.6 \mathrm{~L}$ are shown for five different injection angles $\left(30^{\circ}, 60^{\circ}, 94^{\circ}, 110^{\circ}\right.$, and $\left.140^{\circ}\right)$. The number of injection is assumed to be two. The profile of nanofluid flow is parabolic. Also, the nanofluid has a velocity on the walls due to the slip velocity condition. The nanofluid velocity and its maximum increase on the central line of

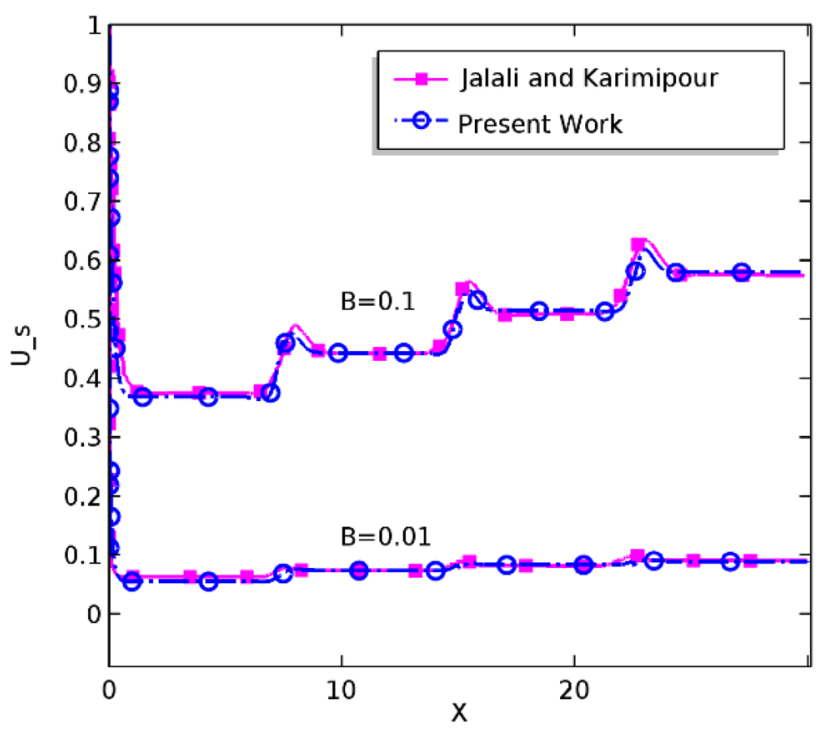

Fig. 2 Non-dimensional slip velocity profile for $\operatorname{Re}=10$ and $\varphi=0.02$

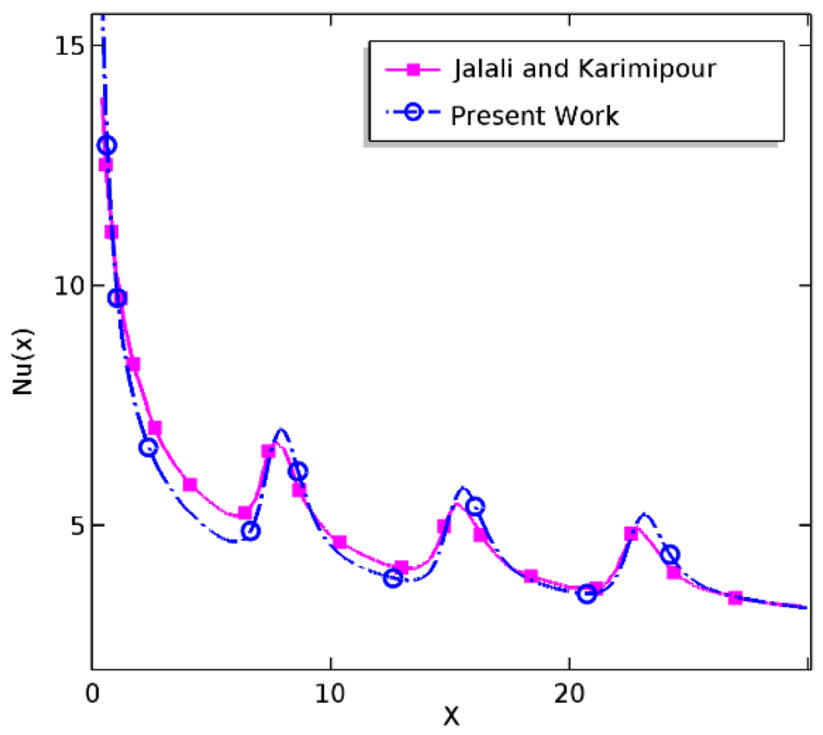

Fig. 3 Local Nusselt number for $\operatorname{Re}=10$ and $\varphi=0.02$

the channel with the injection angle up to $94^{\circ}$ and then decrease. Figure 5 demonstrates the changes of the temperature of the nanofluid flow along the line $X=0.6 \mathrm{~L}$ for different injection angles. It is found that the temperature 


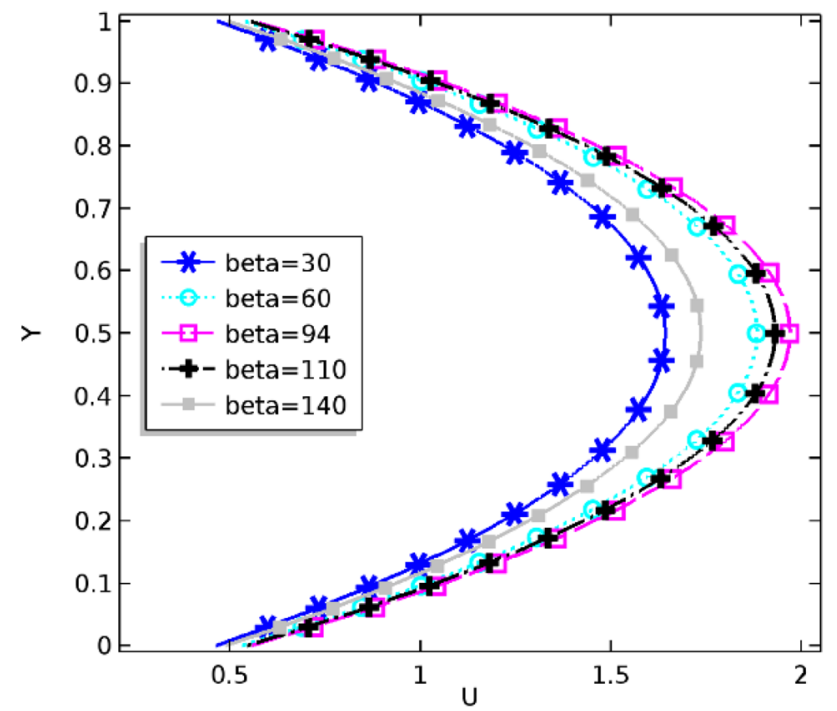

Fig. 4 Dimensionless velocity of nanofluid along the line $X=0.6 \mathrm{~L}$ for different injection angles

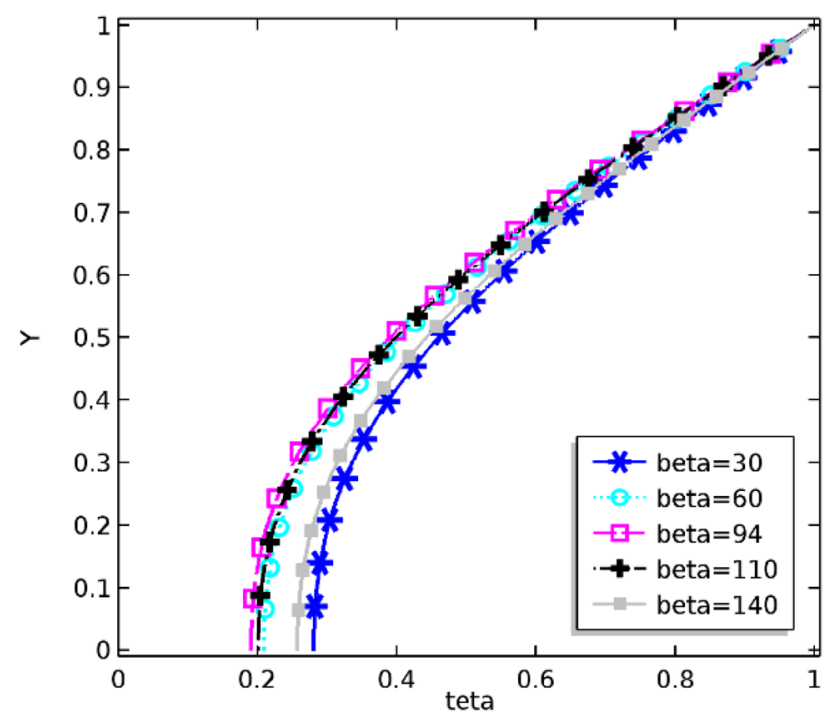

Fig. 5 Temperature profile of nanofluid along the line $X=0.6 \mathrm{~L}$ for different injection angles

increases with the injection angle up to $94^{\circ}$ and then decreases. In other words, the injection angle of $94^{\circ}$ is an optimal angle for heat and fluid flow when the number of injection is two.

The impact of the injection angle on the slip velocity is shown in Fig. 6 . The slip velocity is maximum at the entrance and then decreases by increasing $X$. It is slightly increased when the fluid reaches an injection and eventually, after a slight decrease, reaches a constant value. It should be pointed out that the slip velocity increases with

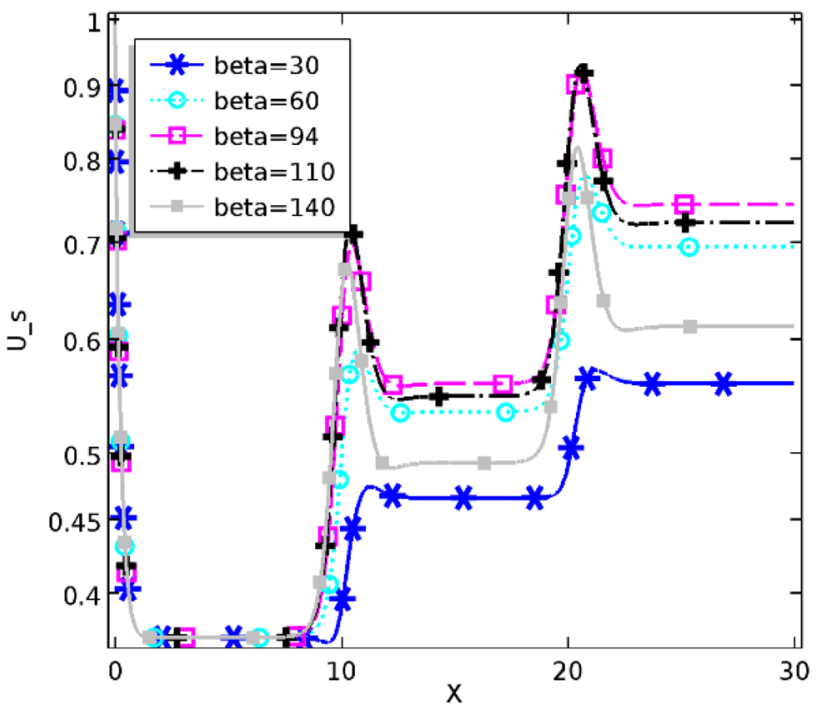

Fig. 6 Slip velocity for $\operatorname{Re}=10, \varphi=0.02, B=0.1$ and different injection angles

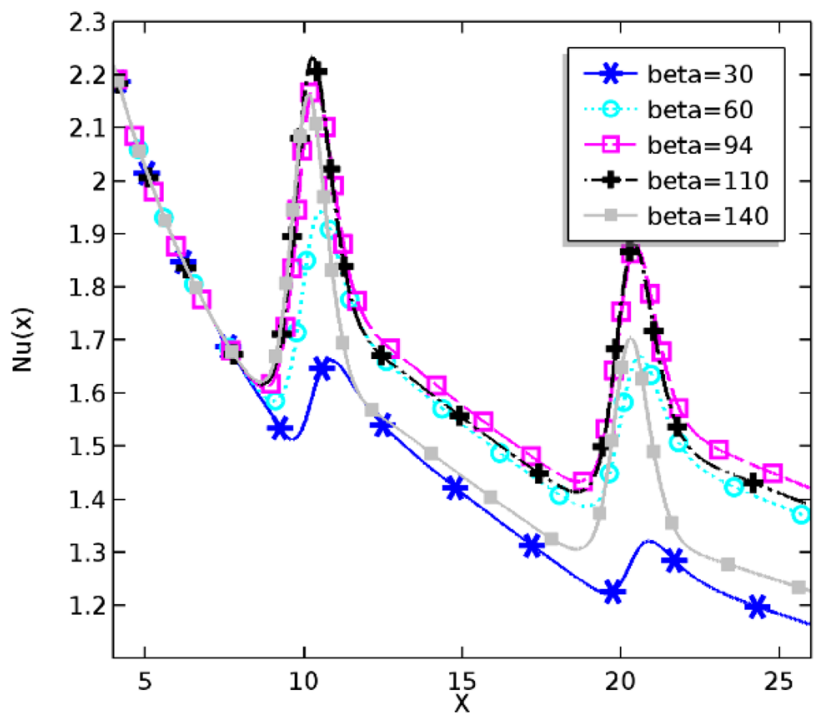

Fig. $7 \mathrm{Nu}_{\mathrm{x}}$ versus $\mathrm{X}$ for $\mathrm{Re}=10, \varphi=0.02, \mathrm{~B}=0.1$ and various injection angles

the angle of injection. The maximum slip velocity corresponds to the injection angle of $94^{\circ}$.

The impact of the injection angle on $\mathrm{Nu}_{x}$ is shown in Fig. 7. At the microchannel entrance, $\mathrm{Nu}$ is maximum due to the maximum temperature gradient between the nanofluid and the microchannel walls. Nu decreases gradually by increasing $X$ and decreasing the temperature gradient. Also, Nu decreases with the angle of injection. Again, the maximum Nusselt number corresponds to the injection angle of $94^{\circ}$. This is in agreement with the previous studies; 
as the injection angle increases, the slip velocity and, consequently, the Nusselt number increase.

\subsection{Effect of the number of injection}

The impact of the number of injections on the velocity and temperature fields is investigated. Figures 8 and 9 indicate the variation of velocity and dimensionless temperature along the line $X=0.5 \mathrm{~L}$ for 2,4 , and 6 injections on the lower wall with the angle of $94^{\circ}$, respectively. An increase in the number of injections does not significant impact on velocity and temperature fields. Figure 9 demonstrates that the number of injections has a little effect on dimensionless temperature. At $Y=0.5, \theta=0.326,0.335$, and 0.343 for $\mathrm{N}=2,4$, and 6 , respectively. The variations of velocity distribution also exhibit that the number of injections does not a significant effect on flow hydrodynamics.

Figure 10 illustrates the impact of the number of injections on the dimensionless slip velocity. The velocity increases on each injection and then decreases slightly along the channel. It finally reaches a constant value at the end of the channel. The constant amount of slip velocity at the end of the microchannel is equal for different number of injections due to constant injection flow rate. The oscillation and slop of these changes decrease with the number of injections. In general, the slip velocity decreases with the number of injections. In addition, the relative maximum points of the diagrams are correlated with the increase in the number of injections, while the relative minimum points of the diagrams are the same at the beginning and the end of the microchannel and at $\mathrm{X}=0.5 \mathrm{~L}$ for different number of injections.

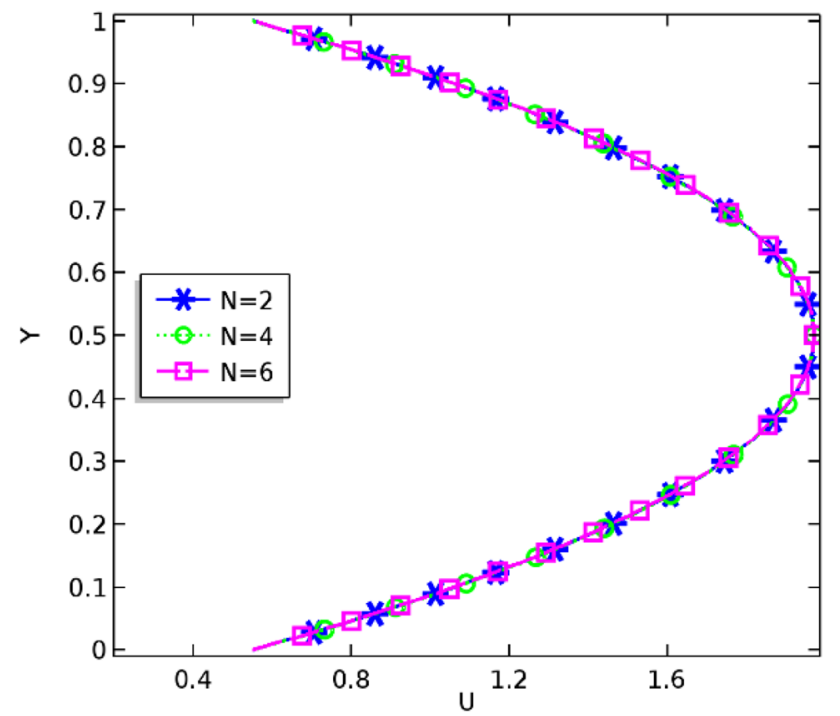

Fig. 8 Dimensionless velocity of nanofluid along the line $X=0.5 \mathrm{~L}$ for different number of injection

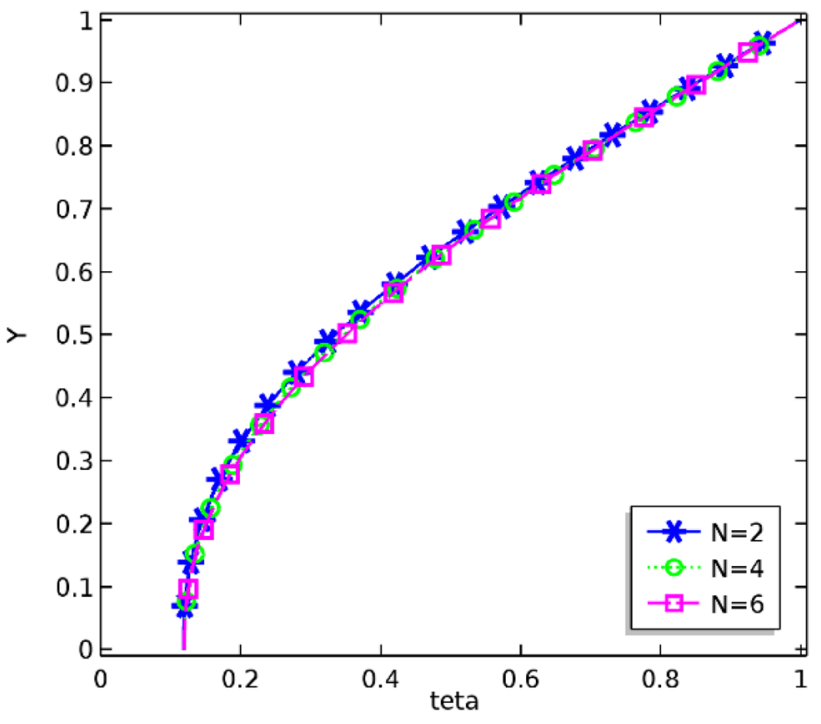

Fig. 9 Dimensionless temperature profile of nanofluid along the line $X=0.5 \mathrm{~L}$ for different number of injection

The effect of increasing and decreasing the number of injections on the local Nusselt number of the microchannel walls is shown in Fig. 11. As it is seen, the initial and final points of the diagrams are equal. By enhancing the number of injections, the nanofluid flow is earlier reached thermal fully development. Therefore, the variation of Nu decreases with the number of injection.

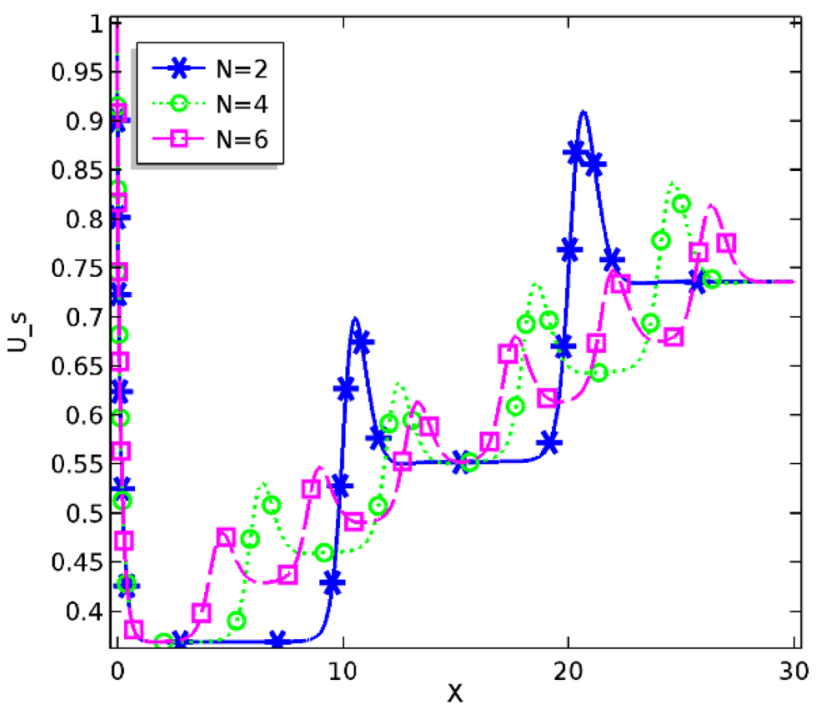

Fig. 10 Dimensionless temperature profile of nanofluid along the line $X=0.5 \mathrm{~L}$ for different 


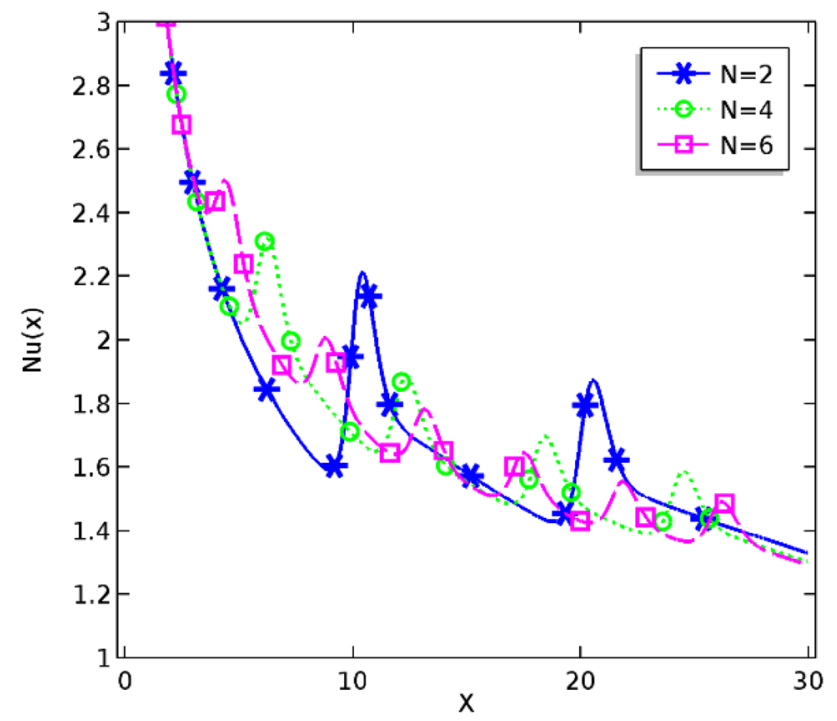

Fig. 11 Local Nusselt number along the microchannel for different number of injection

\subsection{Effect of the volume fraction of nanoparticles}

In this section, the heat transfer between the nanofluid and the microchannel wall is investigated for two injections with the angle of $94^{\circ}$ on the lower wall for different volume fractions of nanoparticles. Figure 12 shows the non-dimensional temperature profile of nanofluid flow along the line $X=0.5 \mathrm{~L}$ for different values of $\varphi$. The non-dimensional temperature increases by increasing $\varphi$ and nanofluid thermal conductivity. Figure 13 indicates that $\mathrm{Nu}$ increases with $\varphi$. The present results confirm

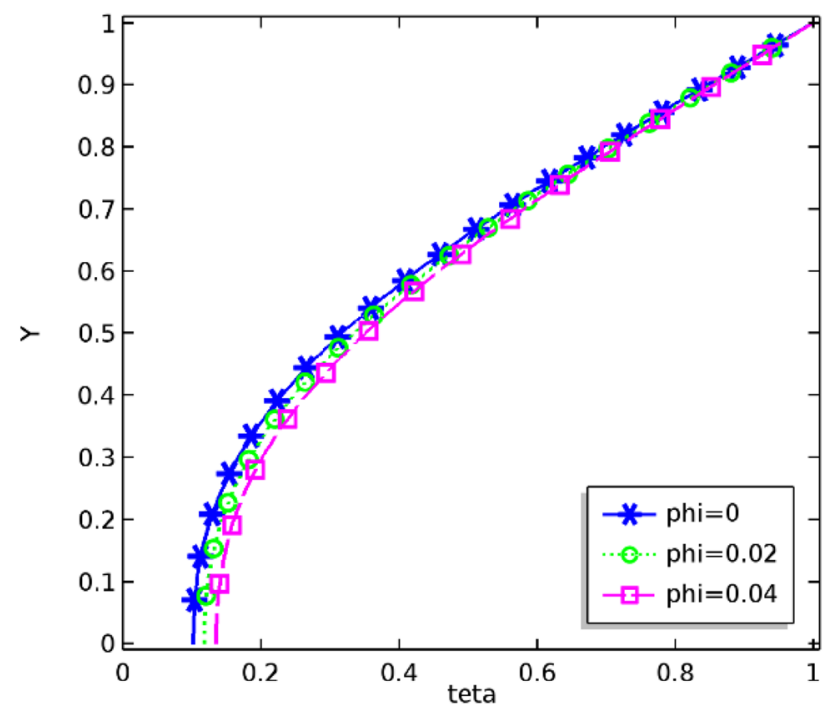

Fig. 12 Dimensionless temperature profile of nanofluid along the line $X=0.5 \mathrm{~L}$ for different values of $\varphi$

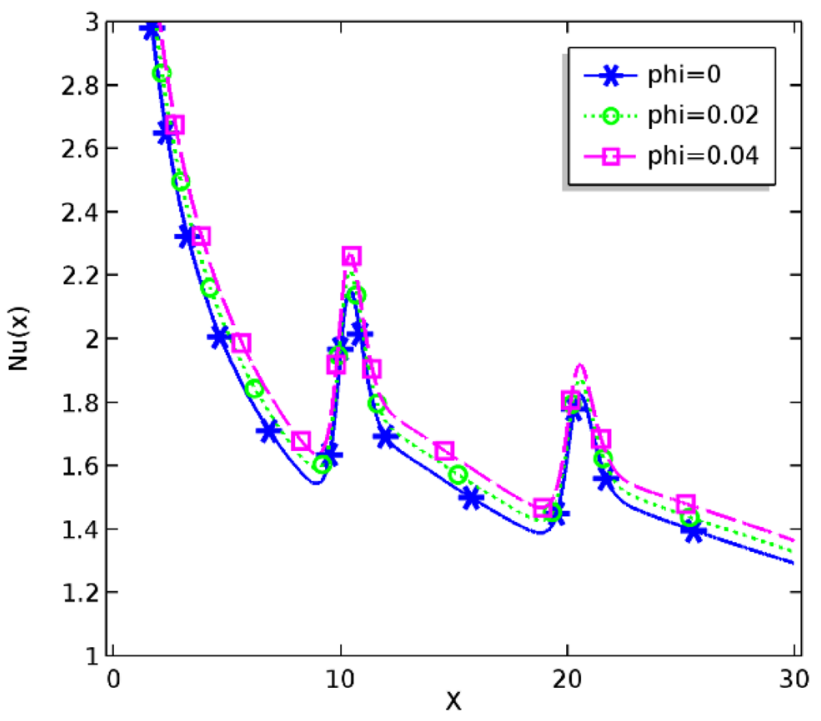

Fig. 13 Local Nusselt number along the line $X=0.5 \mathrm{~L}$ for different values of $\varphi$

the results obtained by Jalali and Karimipour [16] who studied the effect of volume fraction on average Nusselt number. They showed that the slope of enhancement of Nusselt number increases with the Reynolds number. In the present work, the difference between dimensionless temperature is higher at the lower wall compared to the upper one.

\section{Conclusions}

This paper studied forced convection of water $/ \mathrm{Al}_{2} \mathrm{O}_{3}$ nanofluid in a horizontal microchannel with cross-flow injection. The slip velocity condition was considered on the walls of the microchannel. There were a number of injection holes on the lower wall. The following results were obtained:

- The maximum Nu occurs at the injection angle of $94^{\circ}$ as an optimal injection angle.

- As the number of injections increases, Nu increases. Nu does not change at the microchannel output by changing the number of injections.

- Increasing the injection angle to reach the optimal injection angle results in an enhancement in the slip velocity on the microchannel walls. Then, the slip velocity decreases by increasing the injection angle.

- Nanofluid thermal conductivity and Nu increase with $\varphi$. 


\section{Compliance with ethical standards}

Conflict of interest The authors declare that they have no competing interests.

\section{References}

1. Masuda H, Ebata A, Teramae K (1993) Alteration of thermal conductivity and viscosity of liquid by dispersing ultra-fine particles. Dispersion of $\mathrm{Al}_{2} \mathrm{O}_{3}, \mathrm{SiO}_{2}$ and $\mathrm{TiO}_{2}$ ultra-fine particles. Netsu Bussei 7:227-233

2. Nazari M, Ashouri M, Kayhani MH (2014) Experimental investigation of forced convection of nanofluids in a horizontal tube filled with porous medium. Mech Modares 14:109-116 (in Persian)

3. Raisi A, Ghasemi B, Aminossadati SM (2011) A numerical study on the forced convection of laminar nanofluid in a microchannel with both slip and no-slip conditions. Numer Heat Transf Part A Appl 59:114-129

4. Akbarinia A, Abdolzadeh M, Laur R (2011) Critical investigation of heat transfer enhancement using nanofluids in microchannels with slip and non-slip flow regimes. Appl Therm Eng 31:556-565

5. Anoop K, Sadr R, Yu J, Kang S, Jeon S, Banerjee D (2012) Experimental study of forced convective heat transfer of nanofluids in a microchannel. Int Commun Heat Mass Transf 39(9):1325-1330

6. Togun $\mathrm{H}$, Ahmadi G, Abdulrazzaq T, Shkarah AJ, Kazi SN, Badarudin A, Safaei MR (2015) Thermal performance of nanofluid in ducts with double forward-facing steps. J Taiwan Inst Chem Eng 47:28-42

7. Nemati H, Farhadi M, Sedighi K, Ashorynejad H, Fattahi EJSI (2012) Magnetic field effects on natural convection flow of nanofluid in a rectangular cavity using the Lattice Boltzmann model. Sci Iran 19:303-310

8. Jung J-Y, Oh H-S, Kwak H-Y (2006) Forced convective heat transfer of nanofluids in microchannels. In: ASME 2006 international mechanical engineering congress and exposition, pp 327-332

9. Olofinkua J (2018) On the effect of nanofluid flow and heat transfer with injection through an expanding or contracting porous channel. J Comput Appl Mech 49(1):1-8

10. Malvandi A, Ganji DD (2014) Brownian motion and thermophoresis effects on slip flow of alumina/water nanofluid inside a circular microchannel in the presence of a magnetic field. Int $J$ Therm Sci 84:196-206

11. Afrand M, Karimipour A, Nadooshan AA, Akbari M (2016) The variations of heat transfer and slip velocity of FMWNT-water nano-fluid along the micro-channel in the lack and presence of a magnetic field. Physica E 84:474-481

12. Li J, Kleinstreuer C (2008) Thermal performance of nanofluid flow in microchannels. Int J Heat Fluid Flow 29(4):1221-1232

13. Aina B, Bukar Malgwi $P$ (2019) MHD fluid and heat transfer in an inclined micro-porous-channel. Nonlinear Eng 8(1):755-763

14. Jha BK, Oni MO, Aina B (2016) Role of suction/injection on steady fully developed mixed convection flow in a vertical parallel plate microchannel. Ain Shams Eng J 9:1289-1301

15. López A, Ibáñez G, Pantoja J, Moreira J, Lastres O (2017) Entropy generation analysis of MHD nanofluid flow in a porous vertical microchannel with nonlinear thermal radiation, slip flow and convective-radiative boundary conditions. Int J Heat Mass Transf 107:982-994

16. Jalali E, Karimipour A (2018) Simulation the effects of crossflow injection on the slip velocity and temperature domain of a nanofluid flow inside a microchannel. Int J Numer Methods Heat Fluid Flow. https://doi.org/10.1108/HFF-04-2018-0149

17. Uysal C, Korkmaz ME (2019) Estimation of entropy generation for Ag-MgO/water hybrid nanofluid flow through rectangular minichannel by using artificial neural network. J Polytech 22(1):41-51

18. Akinshilo AT (2018) Flow and heat transfer of nanofluid with injection through an expanding or contracting porous channel under magnetic force field. Eng Sci Technol Int J 21(3):486-494

19. Jahanbakhshi A, Ahmadi Nadooshan A, Bayareh M (2018) Magnetic field effects on natural convection flow of a non-Newtonian fluid in an L-shaped enclosure. J Therm Anal Calorim 133:1407-1416

20. Sepyani M, Shateri A, Bayareh M (2019) Investigating the mixed convection heat transfer of a nanofluid in a square chamber with a rotating blade. J Therm Anal Calorim 135:609-623

21. Bayareh M, Kianfar A, Kasaeipour A (2018) Mixed convection heat transfer of water-alumina nanofluid in an inclined and baffled c-shaped enclosure. J Heat Mass Transf Res 5(2):129-138

22. Shirazi M, Shateri A, Bayareh M (2018) Numerical investigation of mixed convection heat transfer of a nanofluid in a circular enclosure with a rotating inner cylinder. J Therm Anal Calorim 133(2):1061-1073

Publisher's Note Springer Nature remains neutral with regard to jurisdictional claims in published maps and institutional affiliations. 